\section{Patient choice of primary care practitioner for orofacial symptoms}

\author{
G. W. Bell, ${ }^{1}$ G. L. F. Smith, ${ }^{2}$ J. M. Rodgers, ${ }^{3}$ R. W. Flynn ${ }^{4}$ and C. H. Malone ${ }^{5}$
}

VERIFIABLE CPD PAPER
IN BRIEF

- Most patients are unaware of the training that dentists receive in non-dental orofacial diseases.

- General medical practitioners have provided an effective oral health service for many years with little acknowledgement, support or training.

- Dentists with support and continuing postgraduate development may contribute to a more comprehensive provision of oral healthcare.

Objective To determine patients' preferences regarding consultation of medical or dental practitioners for various orofacial symptoms, including patients' perceptions of practitioners' training and ability to diagnose and treat these symptoms. Method Patients attending oral and maxillofacial clinics in Dumfries \& Galloway, Scotland in relation to a variety of complaints were invited to complete a questionnaire. Results From a sample size of 254 patients, 220 correctly completed questionnaires were received. This showed 69\% of patients regarded medical practitioners as being better trained to diagnose and treat non-dental orofacial symptoms. Eighty percent of patients regarded medical practitioners as being more accessible when booking an appointment. Seventy-eight percent of patients did not regard charges for dental care as being an important factor when deciding which practitioner they should consult. Conclusion Despite the significant differences between medical and dental practitioners in undergraduate and postgraduate training in orofacial disease, most patients would choose to visit a medical rather than dental practitioner. While these results suggest the need for postgraduate educational support for medical practitioners in treating orofacial pain and oral mucosal disease, they also imply a need for change in the concept of provision of oral healthcare by general dental practitioners.

\section{INTRODUCTION}

Patients with symptoms involving the orofacial region may approach a general medical or dental practitioner or a community pharmacist. Patients often only seek immediate relief of symptoms and not necessarily diagnosis and treatment. The care, advice and treatment that patients receive will reflect the training and experience of the particular healthcare professional and facilities available. Referral between primary care general dental and medical practitioners often

\footnotetext{
${ }^{*}$ Maxillofacial Associate Specialist, Dumfries \& Galloway Royal Infirmary, Bankend Road, Dumfries, DG $4 \mathrm{AP} ;{ }^{2}$ Consultant in Oral Medicine, Glasgow Dental Hospital \&t School, Sauchiehall Street, Glasgow, G2 3JZ; ${ }^{3}$ Specialist in Dental Public Health, NHS Fife, Cameron Hospital, Windygates, Fife, KY8 5RR; ${ }^{4}$ Statistician, Research \& Development Support Unit, Dumfries \& Galloway Royal Infirmary, Bankend Road, Dumfries, DG1 4AP; ${ }^{5} \mathrm{GP}$ with Special Interest in Dermatology, Lockerbie Medical Practice, NHS Dumfries \&t Galloway, Lockerbie, DG11 2BJ

*Correspondence to: Dr Garmon W. Bell

Email: garmon.bell@nhs.net
}

\section{Refereed Paper}

Accepted 29 February 2008

DOI: $10.1038 /$ sj.bdj.2008.523

${ }^{\bullet}$ British Dental Journal 2008; 204: 669-673 occurs when a diagnosis is not reached, and can cause a delay in treatment. Following failure to diagnose and treat in the primary healthcare setting, referral to a medical or dental specialist may be generated. Delays in diagnosis may prolong painful symptoms and contribute to patient anxiety.

This study set out to investigate patients' perceptions of the training, experience and skills of medical and dental practitioners in treating orofacial symptoms. The study also sought to determine patients' preference of medical or dental practitioner for a variety or dental and non-dental orofacial symptoms.

\section{METHOD}

The study was undertaken over a period of two months during Spring 2007, and sought the opinions of patients attending the clinics of an oral and maxillofacial surgery department in Stranraer and Dumfries, in NHS Dumfries and Galloway, Scotland, for a variety of clinical conditions. A questionnaire collected information on the source of referral to the clinic, access to appointments with a general dental or medical practitioner, and perception of training and ability of medical and dental practitioners to treat orofacial problems, excluding those directly related to teeth and gingival tissues. In addition patients were asked to make a choice of which practitioner, medical or dental, they would consult for a variety of orofacial symptoms.

Patient opinions were recorded on printed questionnaires while waiting in the reception area prior to their consultation. Patient responses were anonymous. Collected data was processed and recorded on a spreadsheet (Microsoft ${ }^{\circledR}$ Office Excel, Microsoft Corporation). The data were analysed using SPSS version 14.0. Analysis of associations was assessed using cross-tabulations and chi square tests.

\section{RESULTS}

There were 254 new and return patients approached and invited to complete the questionnaire. Two patients declined as they viewed the questionnaire as inappropriate due to attendance for a non-orofacial problem. There were 32 
Table 1 Cross tabulation of patients' answers and referring practitioner

Who do you think to be the most able to treat problems of the mouth or jaws? (excluding treatment to the teeth or gums)

Who do think has had the most training in diseases of the mouth/face/jaws? (excluding treatment to the teeth or gums)

Who would you rather visit if you had a problem of the mouth/jaw? (excluding treatment to the teeth or gums)

Which practitioner is most accessible when booking an appointment?

\begin{tabular}{|c|c|c|c|c|c|c|c|c|}
\hline & \multicolumn{6}{|c|}{ Referred by doctor/dentist } & \multirow{3}{*}{$\begin{array}{c}\text { Chi } \\
\text { square }\end{array}$} & \multirow{3}{*}{$\mathrm{p}$} \\
\hline & \multicolumn{2}{|c|}{ Dentist } & \multicolumn{2}{|c|}{ Doctor } & \multicolumn{2}{|c|}{ Total } & & \\
\hline & $\mathrm{n}$ & $(\%)$ & $\mathrm{n}$ & $(\%)$ & $\mathrm{n}$ & $(\%)$ & & \\
\hline Dentist & 64 & $(57.1)$ & 25 & $(23.1)$ & 89 & $(40.5)$ & 26.4 & $<0.001$ \\
\hline Doctor & 48 & $(42.9)$ & 83 & (76.9) & 131 & $(59.5)$ & & \\
\hline Dentist & 59 & $(52.7)$ & 29 & $(26.9)$ & 88 & $(40.0)$ & 15.3 & $<0.001$ \\
\hline Doctor & 53 & $(47.3)$ & 79 & $(73.1)$ & 132 & $(60.0)$ & & \\
\hline Dentist & 50 & $(44.6)$ & 18 & $(16.7)$ & 68 & (30.9) & 20.2 & $<0.001$ \\
\hline Doctor & 62 & (55.4) & 90 & (83.3) & 152 & (69.1) & & \\
\hline Dentist & 33 & $(29.5)$ & 12 & $(11.1)$ & 45 & (20.5) & 11.4 & 0.001 \\
\hline Doctor & 79 & (70.5) & 96 & (88.9) & 175 & (79.5) & & \\
\hline
\end{tabular}

Table 2 Cross tabulation of patients' views on payment against referring practitioner and choice of practitioner

\begin{tabular}{|c|c|c|c|c|c|c|c|c|c|}
\hline & & \multicolumn{6}{|c|}{$\begin{array}{l}\text { Does the fact that you have to pay to see your dentist but not pay } \\
\text { to see your doctor influence who you would attend for a problem } \\
\text { of the mouth or jaws? }\end{array}$} & \multirow{3}{*}{$\begin{array}{c}\text { Chi } \\
\text { square }\end{array}$} & \multirow{3}{*}{$p$} \\
\hline & & \multicolumn{2}{|c|}{ Yes } & \multicolumn{2}{|c|}{ No } & \multicolumn{2}{|c|}{ Total } & & \\
\hline & & $n$ & $(\%)$ & $n$ & $(\%)$ & $\mathrm{n}$ & $(\%)$ & & \\
\hline \multirow{2}{*}{ Were you referred by your doctor/dentist? } & Dentist & 21 & $(42.9)$ & 91 & (53.2) & 112 & (50.9) & 1.6 & 0.201 \\
\hline & Doctor & 28 & (57.1) & 80 & $(46.8)$ & 108 & (49.1) & & \\
\hline \multirow{2}{*}{$\begin{array}{l}\text { Who would you rather visit if you had a } \\
\text { problem of the mouth/jaw? (excluding } \\
\text { treatment to the teeth or gums) }\end{array}$} & Dentist & 16 & $(32.7)$ & 52 & $(30.4)$ & 68 & $(30.9)$ & 0.090 & 0.764 \\
\hline & Doctor & 33 & (67.3) & 119 & (69.6) & 152 & (69.1) & & \\
\hline
\end{tabular}

questionnaires deemed unusable due to either incompletion of particular sections, or of double ticking of options when only one option had been requested. There were therefore 220 correctly completed questionnaires suitable for statistical analysis, giving a response rate of $87 \%$.

Results showed that $49 \%$ of patients had been referred from their medical practitioner, while 51\% of patients had been referred by their dental practitioner. The majority (83\%) of patients regarded themselves as being registered with a general dental practitioner. Of the $17 \%$ of patients who did not have regular access to a dentist, 65\% reported that they had been previously registered or in regular attendance.

The patients' responses to four questions relating to which practitioner they thought would be most able to treat problems of the mouth and jaws, and had the most training in treating orofacial problems, including choice of which practitioner they would visit with an orofacial problem and who they believed to be most accessible, are outlined in Table 1. The table shows that patients chose their medical practitioner over their dental practitioner in all four situations, and by a large margin. Chi square analysis investigated the strength of association between patients' choices and the practitioner who referred them. In each case there was a highly significant association between the patients' choice of practitioner and the practitioner from whom they were referred, indicating that while most patients would choose their medical practitioner, patients appear to have more confidence in the practitioner that they were referred by.

Only 22\% of patients regarded having to pay to see a dental practitioner but not having to pay to see a medical practitioner as influencing who they would consult with an orofacial problem. A chi square analysis of the strength of association between patients' views on payment against which practitioner referred the patient and which practitioner the patients would choose to visit is outlined in Table 2. There was no significant association between patients' views on fee paying against the practitioner from whom they were referred, or from which practitioner they would choose to visit.

The patients' choices when asked to choose between a medical or dental practitioner regarding consultation for a variety of orofacial problems are outlined in Table 3. Chi square analysis was used to test the strength of any association between patients' choice of practitioner for various symptoms and the practitioner from whom they were referred. Fisher's exact test was used to analyse the strength of any association for responses to toothache and a neck 
swelling because of low expected cell counts. This shows that in some cases, especially for the more obvious dental problems, the patients did choose to consult their dentist but consistently, as with the results in Table 1, they chose to consult their medical practitioner for orofacial problems.

\section{DISCUSSION}

The aim of this study was, by assessing patients' preferences regarding consultation of medical or dental practitioners

Table 3 Cross tabulation of patients' choice of practitioner for various symptoms against source of referral

Toothache

Lump on gum

Bad taste in mouth

Bad breath

Bleeding gums

Clicking jaw joint

Restricted mouth opening

Mouth ulcers

\section{Pain under a denture}

Lump on roof of mouth

Pain after removal of tooth

Tooth socket that is slow to heal

\section{Swelling under tongue}

Swelling of neck just below lower jaw

Jaw ache with headache

Facial swelling with toothache

Lump on lip

White or red patch on cheek or tongue

Sore cheeks or tongue
Referred by doctor/dentist

\begin{tabular}{|c|c|c|c|c|c|c|c|c|}
\hline & \multicolumn{6}{|c|}{ Referred by doctor/dentist } & \multirow{3}{*}{$\begin{array}{c}\text { Chi } \\
\text { square }\end{array}$} & \multirow{3}{*}{$p$} \\
\hline & \multicolumn{2}{|c|}{ Dentist } & \multicolumn{2}{|c|}{ Doctor } & \multicolumn{2}{|c|}{ Total } & & \\
\hline & $\mathrm{n}$ & (\%) & $\mathrm{n}$ & (\%) & $\mathrm{n}$ & (\%) & & \\
\hline Dentist & 110 & (98.2) & 104 & (96.3) & 214 & (97.3) & & 0.439 \\
\hline Doctor & 2 & $(1.8)$ & 4 & (3.7) & 6 & (2.7) & & \\
\hline Dentist & 80 & (71.4) & 55 & $(50.9)$ & 135 & (61.4) & 9.7 & 0.002 \\
\hline Doctor & 32 & $(28.6)$ & 53 & $(49.1)$ & 85 & (38.6) & & \\
\hline Dentist & 66 & $(58.9)$ & 47 & $(43.5)$ & 113 & (51.4) & 5.2 & 0.022 \\
\hline Doctor & 46 & $(41.1)$ & 61 & $(56.5)$ & 107 & $(48.6)$ & & \\
\hline Dentist & 62 & (55.4) & 42 & (38.9) & 104 & $(47.3)$ & 6.0 & 0.014 \\
\hline Doctor & 50 & $(44.6)$ & 66 & (61.1) & 116 & $(52.7)$ & & \\
\hline Dentist & 93 & (83.0) & 75 & (69.4) & 168 & (76.4) & 5.6 & 0.018 \\
\hline Doctor & 19 & $(17.0)$ & 33 & (30.6) & 52 & (23.6) & & \\
\hline Dentist & 27 & $(24.1)$ & 14 & $(13.0)$ & 41 & (18.6) & 4.5 & 0.034 \\
\hline Doctor & 85 & (75.9) & 94 & (87.0) & 179 & (81.4) & & \\
\hline Dentist & 22 & (19.6) & 13 & (12.0) & 35 & (15.9) & 2.4 & 0.123 \\
\hline Doctor & 90 & (80.4) & 95 & (88.0) & 185 & (84.1) & & \\
\hline Dentist & 47 & (42.0) & 30 & (27.8) & 77 & (35.0) & 4.9 & 0.027 \\
\hline Doctor & 65 & $(58.0)$ & 78 & $(72.2)$ & 143 & (65.0) & & \\
\hline Dentist & 105 & (93.8) & 91 & (84.3) & 196 & (89.1) & 5.1 & 0.024 \\
\hline Doctor & 7 & (6.3) & 17 & (15.7) & 24 & (10.9) & & \\
\hline Dentist & 43 & (38.4) & 20 & (18.5) & 63 & (28.6) & 10.6 & 0.001 \\
\hline Doctor & 69 & (61.6) & 88 & (81.5) & 157 & (71.4) & & \\
\hline Dentist & 96 & (85.7) & 90 & (83.3) & 186 & (84.5) & 0.2 & 0.625 \\
\hline Doctor & 16 & (14.3) & 18 & (16.7) & 34 & (15.5) & & \\
\hline Dentist & 95 & (84.8) & 84 & (77.8) & 179 & (81.4) & 1.8 & 0.180 \\
\hline Doctor & 17 & (15.2) & 24 & (22.2) & 41 & (18.6) & & \\
\hline Dentist & 24 & $(21.4)$ & 8 & (7.4) & 32 & (14.5) & 8.7 & 0.003 \\
\hline Doctor & 88 & (78.6) & 100 & (92.6) & 188 & (85.5) & & \\
\hline Dentist & 7 & (6.3) & 2 & (1.9) & 9 & (4.1) & & 0.171 \\
\hline Doctor & 105 & (93.8) & 106 & (98.1) & 211 & (95.9) & & \\
\hline Dentist & 16 & (14.3) & 4 & (3.7) & 20 & (9.1) & 7.4 & 0.006 \\
\hline Doctor & 96 & (85.7) & 104 & (96.3) & 200 & (90.9) & & \\
\hline Dentist & 93 & (83.0) & 82 & (75.9) & 175 & (79.5) & 1.7 & 0.191 \\
\hline Doctor & 19 & (17.0) & 26 & (24.1) & 45 & (20.5) & & \\
\hline Dentist & 9 & (8.0) & 6 & (5.6) & 15 & (6.8) & 0.5 & 0.466 \\
\hline Doctor & 103 & $(92.0)$ & 102 & (94.4) & 205 & (93.2) & & \\
\hline Dentist & 8 & (7.1) & 4 & (3.7) & 12 & (5.5) & 1.3 & 0.261 \\
\hline Doctor & 104 & (92.9) & 104 & (96.3) & 208 & (94.5) & & \\
\hline Dentist & 8 & (7.1) & 5 & (4.6) & 13 & (5.9) & 0.6 & 0.429 \\
\hline Doctor & 104 & (92.9) & 103 & (95.4) & 207 & (94.1) & & \\
\hline
\end{tabular}


for various orofacial symptoms, to promote discussion around which primary healthcare professional is best suited to diagnosing and treating symptoms of the orofacial region, and whom patients should be advised to consult.

In the present study the majority of patients chose to consult a medical practitioner rather than a dental practitioner for a non-dental orofacial problem. This is similar to a survey of patients attending a rapid access clinic for suspected oral cancer in which 59\% of patients had contacted their medical practitioner about an oral complaint. ${ }^{1}$ Another study of patient choice of practitioner in relation to mouth ulcers showed that $69 \%$ of patients expressed a preference for their general medical practitioner. ${ }^{2}$ A proportion of patients also prefer to consult a medical rather than a dental practitioner for specific dental complaints, ${ }^{3}$ although in some of the cases the direct dental relevance may not be known to the patient and is also often not recognised by the medical practitioner. ${ }^{4}$ This pattern of patient behaviour is not unique to the United Kingdom..$^{5}$ The results from this study suggest that most patients regard medical practitioners as having had more training and therefore as more able to deal with non-dental orofacial complaints.

Patients' concepts of the clinical role of medical and dental practitioners are almost certainly influenced by their experiences and by the perceptions of their family and peers. ${ }^{6,7}$ Many patients do not appreciate the broad education that dental undergraduates in the United Kingdom receive. ${ }^{8}$ Most patients' experiences are of the technical/surgical model of care that constitutes the work load of most general dental practitioners. Most patients will therefore only perceive what is made obvious to them, and if dental surgeons are not frequently seen to be practising comprehensive oral healthcare by their patients, then patients will not associate dentists with the management of non-dental orofacial disease. This may explain why this study has shown that patients will choose to visit their general medical practitioner.

The General Dental Council (GDC) has recognised the need for dental graduates to be able to practise independently in the general practice environment, to recognise their limitations and refer when appropriate. ${ }^{9}$ The GDC recognises the importance of diagnosis of oral mucosal disease and orofacial pain. ${ }^{10}$ Whereas competency in minor soft tissue surgery is required, only knowledge of the diagnosis and management of oral mucosal disease and orofacial pain are required rather than a demonstration of practical competence. ${ }^{10}$ Dental undergraduates have a considerable proportion of their training devoted to the investigation, diagnosis and treatment of orofacial disease, while most medical undergraduates have little training. ${ }^{11}$ Throughout their working lives, dental practitioners have further opportunities to update their knowledge and skills in oral medicine, oral pathology, oral microbiology and oral surgery in their continuing professional development.

Dental practitioners are therefore ideally placed to identify oral mucosal disease and offer advice and treatment on various orofacial pain syndromes. Dental practitioners have demonstrated their ability to recognise the early signs of oral cancer, often before symptoms arise, and make appropriate urgent referral. ${ }^{12}$ Referral patterns such as these usually result in lesions being detected at an earlier stage, with improved prognostic outcomes for the patient. ${ }^{13}$ Dental practitioners have been shown to be able to perform excisional biopsies on simple benign intra-oral lesions and to discuss the results with patients, but have shown a reluctance to perform incisional biopsies where the diagnosis is not obvious. ${ }^{14}$ This latter practice is appropriate because of the need for accurate biopsy techniques in the case of dysplastic or neoplastic lesions, and the need for appropriate counselling skills and follow-up. ${ }^{15}$ However, most dental practitioners will still refer patients with oral mucosal disease and orofacial pain to a secondary care provider. ${ }^{16,17}$ The same situation also arises with periodontal diseases. ${ }^{18}$ These practices may indicate a lack of confidence in diagnosis and management, despite undergraduate and postgraduate training, or reflect the present system of remuneration in dental primary care. Further research is required to establish this, particularly if undergraduate training is to reflect what is required in primary dental care.

The majority of oral healthcare provided in general dental practice relates to the disease processes of dental caries, pulpal and periapical disease and gingi$\mathrm{val} /$ periodontal disease, and the technical procedures that are attached to such. ${ }^{19}$ The incidence of orofacial pain and oral mucosal disease presenting to general dental practitioners would constitute a small proportion of their workload. Is it therefore appropriate to redirect the nature of dental undergraduate training away from the emphasis on competent provision of technical procedures, to that involving a more medically-based approach to orofacial disease and symptoms? This suggestion has been widely discussed for the last 15 years. ${ }^{20-24}$ However, the additional cost and length of such training to produce what has been called an 'oral physician' is unlikely to benefit patients unless there is a significant decline in the incidence of dental caries, tooth surface loss or periodontal disease during the next three decades. An example of the need to develop and maintain the technical emphasis of dental undergraduate training are countries that have recently joined the European Union. Some of these countries previously trained medical graduates who then later specialised in stomatology, but are now changing to the odontological model. ${ }^{25}$ The Adult Dental Health Survey (UK) has demonstrated that more adults are retaining portions of their dentition until later in life. ${ }^{26}$ A significant proportion of these adults will have heavily restored dentitions that will present restorative challenges in the future, hence the emergence of gerodontology with its restorative emphasis. ${ }^{27-29}$ Also, while the prevalence of dental caries in certain social groups is reducing, the incidence of tooth surface loss is increasing which will place additional demands on the restorative skills of general dental practitioners. ${ }^{30}$ It is therefore unlikely that there will be a shift away from the need for technical dental procedures over the next 30 years.

Medical journals have given space to oral disease but in a much smaller proportion to other aspects of medicine and surgery. ${ }^{31}$ Dental postgraduate 
deaneries are actively involved in the continuing education of dentists in oral disease, while the same topic is barely covered in postgraduate medical calendars. Medical practitioners have access to haematological, biochemical and immunological investigations, and have experience of requesting radiological investigations through the secondary health care system, but may not be aware of the appropriate investigations to request in relation to orofacial symptoms. However, medical practitioners have also shown competence in treating orofacial pain and oral mucosal disease, ${ }^{4}$ and have confidence and experience in prescribing from a full formulary of medications and managing side effects. In contrast, dental practitioners under National Health Service directives have only the Dental Practitioners' Formulary, which does not allow prescription of some of the pharmacological agents used to treat orofacial pain and oral mucosal disease. ${ }^{32}$ There is also a lack of formal referral pathways and communication between general medical and dental practitioners. Dental practitioners may utilise the services of medical practitioners in accessing blood test results and also their wider prescribing powers. The benefits of closer co-operation between medical and dental practitioners have been demonstrated..$^{33}$

In this study most patients reported their general medical practitioner as being more accessible than their dental practitioner. A large proportion of patients also regarded themselves as being registered with a dentist, despite Dumfries \& Galloway having demonstrable difficulties in dental access. ${ }^{34}$ This is possibly related to patients' misunderstanding of the principles of registration with a dentist as compared to that with a medical practitioner. ${ }^{35}$ However, despite access and cost issues as outlined in Tables 1 and 2, most patients would still contact a medical practitioner as outlined in Table 3. Therefore access to, and paying to consult a dental practitioner appears to have little influence on patients' choice of practitioner. The choice of practitioner is possibly related more to patients' perception of the role of a general dental practitioner.

\section{CONCLUSION}

This study adds to evidence that many patients will seek advice and treatment from their medical practitioner rather than a dentist for non-dental orofacial symptoms. This is despite dental practitioners having more training in the recognition of and pathways for referral of orofacial disease. This raises questions about the need for improved patient awareness, as well as undergraduate/postgraduate medical and dental training.

For assistance with data collection and analysis, thank you to Angela Chalmers, Project Administrator, Clinical Governance Department, NHS Dumfries \&t Galloway. For development and planning, thank you to Dr Gwen Baxter, Research Scientist, Research and Development Unit, NHS Dumfries \& Galloway.

1. Rodgers J M, Macpherson L M D, Smith $G L F$, Crighton A J, Carton A T M, Conway D I. Characteristics of patients attending rapid access clinics during the West Of Scotland Cancer Awareness Programme oral cancer campaign. Br Dent J 2007; 202: E28.

2. Gill Y, Scully C. Mouth ulcers: a study of where members of the general public might seek advice. Br Dent J 2007; 202: E16.

3. Mansour M H, Cox S C. Patients presenting to the general practitioner with pain of dental origin. Med J Aust 2006; 185: 64-67.

4. Lockhart P B, Mason D K, Konen J C, Kent M L, Gibson J. Prevalence and nature of orofacial and dental problems in family medicine. Arch Fam Med 2000; 9: 1009-1012.

5. Madrid C, Bouferrache K, Moller P. Why try a doctor when you need a dentist? Oral health and primary care medicine: what are the issues? Rev Med Suisse 2006: 2: 2737-2743

6. Land T. What patients think of dental services. $\mathrm{Br}$ Dent J 2000; 189: 21-24.

7. Finch $\mathrm{H}_{1}$ Keegan J, Ward K. Barriers to the receipt of dental care. London: National Centre for Social Research, 1988.

8. Scully C, Bell C, Porter K, Porter S. Views of dental patients about the education and practice of dentists. Community Dent Oral Epidemiol 1994; 22: 112-113.

9. The General Dental Council. The context of undergraduate dental education. In The first five years. 2nd edition. Part 1 pp 10. London: General Dental Council, 2002. www.qub.ac.uk/cd/docs/first5years.pdf

10. The General Dental Council. Subjects and topics. Specific learning outcomes. In The first five years. 2nd edition. Part 2 pp 28-35. London: General Dental Council, 2002. www.qub.ac.uk/cd/docs/ first5years.pdf

11. McCann P J, Sweeny M P, Gibson J, Bagg J. Training in oral disease, diagnosis and treatment for medical students and doctors in the United Kingdom. Br J Oral Maxillofac Surg 2005; 43: 61-64.

12. Holmes J D, Dierks E J, Homer L D, Potter B E. Is detection of oral and oropharyngeal squamous cancer by a dental health care provider associated with a lower stage at diagnosis? J Oral Maxillofac Surg 2003; 61: 285-291.

13. Allison $\mathrm{P}$, Locker D, Feine J S. The role of diagnostic delays in the prognosis of oral cancer: a review of the literature. Oral Oncol 1998; 34: 161-170.

14. Diamanti N, Duxbury A J, Ariyaratnam S, Macfarlane T V. Attitudes to biopsy procedures in general dental practice. Br Dent J 2002; 192: 588-592.

15. Thomson P J. Specialist opinion. Br Dent J 2006; 200: 242.

16. Glaros A G, Glass E G, Hayden W J. History of treatment received by patients with TMD: a preliminary investigation. J Orofac Pain 1995; 9: 147-151.

17. Warnakulasuriya K A, Johnson N W. Dentists and oral cancer prevention in the UK: opinions, attitudes and practices to screening for mucosal lesions and to counselling patients on tobacco and alcohol use: baseline data from 1991. Oral Dis 1999; 5: 10-14.

18. Sharp G, Durham J A, Preshaw P M. Attitudes regarding specialist referrals in periodontics. BrDent J 2007; 202: E11.

19. Brennan D S, Spencer A J. Trends in service provision among Australian private general dental practitioners over a 20 year period. Int Dent J 2006; 56: 215-223.

20. Assel $L A$. Should dentists become 'oral physicians'? No, dentistry must remain dentistry. J Am Dent Assoc 2004; 135: 439, 441, 443 passim.

21. Giddon D B. Should dentists become 'oral physicians'? Yes, dentists should become 'oral physicians'. J Am Dent Assoc 2004; 135: 438, 440, 442 passim.

22. Baum B J. The dental curriculum: what should be new in the 21st Century? J Public Health Dent 1996; 56: 286-290.

23. Hendricson W D, Cohen P A. Oral healthcare in the 21st century: implications for dental and medical health education. Acad Med 2001; 76: 1181-1206.

24. Mason D. The changing role of the dentist. Br Dent J 1994; 176: 5-9.

25. Scott J. Dental education in Europe: the challenges of variety. J Dent Educ 2003; 67: 69-78. www. jdentaled.org/cgi/reprint/67/1/69.pdf

26. Kelly M, Steele J G, Bradnock $\mathrm{G}$ et al. Adult dental health survey. Oral health in the United Kingdom 1998. London: The Stationery Office, 2000. www. statistics.gov.uk/ssd/surveys/adult_dental_ health_survey.asp

27. Pine $C M$, Pitts N B, Steele J G, Nunn J N, Treasure E. Dental restorations in adults in the UK in 1998 and implications for the future. Br Dent J 2001; 190: 4-8.

28. Nunn J, Morris J, Pine C, Pitts N B, Bradnock G, Steele J. The condition of teeth in the UK in 1998 and implications for the future. Br Dent $J 2000$; 189: 639-644.

29. Steele J G, Treasure E, Pitts N B, Morris J, Bradnock G. Total tooth loss in the United Kingdom in 1998 and implications for the future. Br Dent J 2000; 189: 598-603.

30. Chadwick B L, White D A, Morris A J, Evans D, Pitts $N$ B. Non-carious tooth conditions in children in the UK, 2003. Br Dent J 2006; 200: 379-384.

31. Fraser J. The management of oral conditions. Practitioner 2004; 248: 330, 333-336, 340.

32. Dental practitioners' formulary. In British national formulary 55. London: BMJ Group and RPS Publishing, 2008. www.bnf.org

33. Haughney M G, Devinnie J C, Macphearson L M, Mason D K. Integration of primary care dental and medical services. Br Dent J 1998; 184: 343-347.

34. The Consumers Association. Scottish dental care. London: Consumers Association, 2002. www.which.co.uk/files/application/pdf/ 0206scotsdentistry_br-445-55676.pdf

35. Spedding R L, McKinney L A, Boyd R C, el-Attar $A, M c G a f f i n J$ H. Public knowledge of dental registration and management of common dental problems. Dent Update 1999; 26: 303-306. 